\title{
The effect of oxygen on the fibrinolytic enzyme system in vivo
}

\author{
G. M. CUNNINGHAM, G. BOYD, J. WINDEBANK, F. MORAN, AND \\ G. P. MCNICOL
}

From the University Department of Medicine and the Centre for Respiratory Investigation, Glasgow Royal Infirmary

SUMMARY Arterial hypoxia has been accepted as a potent stimulus to increased fibrinolytic activity in vivo.

This study has shown that significant levels of arterial hypoxaemia induced in healthy volunteers by breathing a hypoxic gas mixture have failed to induce changes in the fibrinolytic enzyme system.

Hypoxia has been widely accepted as a potent stimulus to increased plasma fibrinolytic activity in vivo (Kwaan and McFadzean, 1956; Clarke, Orandi and Cliffton, 1960; Cliffton, Clarke, and Murphy, 1961); in view of the physiological importance of this suggested relationship, the present study was set up to investigate the effect on plasma fibrinolytic activity of healthy volunteers of variations in inspired oxygen content.

\section{Materials and Methods}

Ten normal healthy volunteers aged $22-40$ years, having given their full informed consent, were included in the study. Over a 30-minute period each was exposed to a 15-minute period breathing oxygen at an inspired concentration of $11.5 \%$ and a 15 minute peroid breathing oxygen at an inspired concentration of $21 \%$.

The subjects were paired and the second in each pair breathed the gases in the opposite sequence to the first. The order in which the gases were breathed was randomly allocated to the five pairs. This technique was used to ensure that equal numbers breathed the gases in each order. The subjects were not informed of the sequence in which the gas mixtures were used. Two gas cylinders of air mixtures of $11.5 \%$ and $21 \%$ were prepared and joined by a Y-connector and tubing via a 4-litre anaesthetic bag to a one-way valve box and mouthpiece. Seated comfortably at rest, with a nose clip in position, each subject breathed air from one cylinder via the anaesthetic bag and the expired air was exhausted to atmosphere. After 15 minutes to allow adequate time for equilibration of gases in the body and for Received for publication 8 March 1971. changes in plasma fibrinolytic activity to occur, a sample of venous blood was obtained. The air supply was changed to the other gas cylinder and the subject breathed the new gas mixture with a different oxygen concentration for a further 15 minutes. In three subjects small samples of air from the end of each expiration were collected in a bag over the last five minutes of each 15-minute period using an automatic end-tidal sampler (Mills, 1971); the total volume was then analysed for its oxygen concentration. An estimate of the concentration of oxygen in the alveolar gas was, therefore, obtained and this afforded confirmation that the partial pressures of oxygen in the arterial blood were within the range predicted for each level of oxygen presented to the subject in the inspired air.

The procedure was then repeated with the same volunteers using gas mixtures with oxygen concentration of $21 \%$ and $43.5 \%$. End-tidal sampling was used in nine subjects to confirm that the partial pressure of oxygen in the arterial blood was within predicted levels.

Whole blood was obtained at rest, and again immediately after each mixture was breathed, by clean venepuncture into plastic syringes, the minimum of venous occlusion being used. All subsequent estimations were performed on each sample without knowledge of the gas mixture to which each referred; this was disclosed only after all analyses were completed. The blood was transferred into siliconized centrifuge tubes containing $3.8 \%$ sodium citrate in a dilution of 1 part citrate to 9 parts whole blood and was then centrifuged at $600 \mathrm{~g}$ for 10 minutes.

Five millilitres of whole blood was also placed in plastic tubes containing glass beads immediately 
following venepuncture and one milligram of the fibrinolytic inhibitor tranexamic acid was added to inhibit fibrinolysis in vitro. This specimen was used for the assay of serum fibrin degradation products (FDP) by the method of Merskey, Kleiner, and Johnson (1966) as described by Bonnar, Davidson, Pidgeon, McNicol, and Douglas (1969).

The following estimations were performed on the plasma obtained by centrifugation of the citrated whole blood:

\section{PLASMINOGEN ASSAY}

The method of Remmert and Cohen (1949) as modified by Alkjaersig, Fletcher, and Sherry (1959) was used. This method is described by McNicol and Douglas (1964).

\section{FIBRINOGEN ASSAY}

The plasma fibrinogen levels were measured by the method of Ratnoff and Menzie (1955).

\section{EUGLOBULIN LYSIS TIME}

The test was carried out by the method described by Nilsson and Olow (1962).

\section{UROKINASE SENSITIVITY TEST}

The test was carried out by the method described by Dubber, McNicol, Uttley, and Douglas (1968).

\section{FIBRIN PLATE LYSIS TIME}

The test was carried out by the method described by Nilsson and Olow (1962).

\section{Results}

At the low level of inspired oxygen concentration $(11.5 \%)$, analysis of end-tidal gas indicated a mean partial pressure of oxygen in the alveolar air of $53.9 \mathrm{~mm} \mathrm{Hg}$ compared with a mean partial pressure of $109 \mathrm{~mm} \mathrm{Hg}$ when breathing $21 \%$ oxygen mixture. Assuming a normal alveolar-arterial partial pressure difference for oxygen in these normal subjects of $10 \mathrm{~mm} \mathrm{Hg}$, an average partial pressure of oxygen in the arterial blood of $44 \mathrm{~mm} \mathrm{Hg}$ was obtained with the $11.5 \%$ oxygen mixture and $99 \mathrm{~mm} \mathrm{Hg}$ with the $21 \%$ oxygen mixture. Several subjects reported sensations of light-headedness, dizziness, or head ache whilst breathing or just after breathing the low oxygen mixture and one subject was noted to be cyanosed. Breathing the high oxygen mixture $(43.5 \%$ the average partial pressure of oxygen in the arterial blood was $287 \mathrm{~mm} \mathrm{Hg}$ as compared with $105 \mathrm{~mm}$ $\mathrm{Hg}$ when breathing the $21 \%$ oxygen mixture.

The mean results of the euglobulin lysis times are shown in Table I. No significant alteration iff values was obtained between room air and hypoxis mixture $(P>1)$ or between the hypoxic mixture an stored air. Similarly, no significant change was detected with room air and high concentration of inspired oxygen and between this latter mixture anf stored air. No changes occurred in lysis times in the urokinase sensitivity tests.

The mean results of the assays of fibrinogenz plasminogen, and fibrin degradation products are shown in Table I; no significant differences wers obtained when the different gas mixtures were breathed or when breathing room air in resting conditions. It will also be seen that no lysis occurre in the fibrin plates with any specimen.

\section{Discussion}

The results of these series of experiments suggest that acute changes in the arterial oxygenation of healthy adults are not potent stimuli to alterations in plasma fibrinolytic activity in vivo. The findings with high concentrations of inspired oxygen are in keeping with the results of Lieberman and Kelloge (1967) who failed to detect any increase in plasmintogen activity in the lungs of various strains of mice when exposed to a $90 \%$ oxygen atmosphere.

Our finding is that there was no change in systemic venous plasma fibrinolytic activity in the subject? with significant arterial hypoxaemia; this result is perhaps unexpected in the light of the findings of Kwaan and McFadzean (1956) and Kwaan, Lop and McFadzean (1958) who showed that fibrinolytio activity was increased in ischaemic limbs; they also

\begin{tabular}{|c|c|c|c|c|c|c|}
\hline Test & $\begin{array}{l}\text { Resting } \\
\text { Base-line Value }\end{array}$ & $\begin{array}{l}\text { Oxygen } \\
(11 \cdot 5 \%)\end{array}$ & Stored Air & $\begin{array}{l}\text { Resting } \\
\text { Base-line Value }\end{array}$ & $\begin{array}{l}\text { Oxygen } \\
(43.5 \%)\end{array}$ & Stored Air \\
\hline $\begin{array}{l}\text { Euglobulin lysis time (units) } \\
\text { Fibrinogen (mg/100 ml) } \\
\text { Plasminogen }(\mathrm{c} / \mathrm{ml}) \\
\text { FDP }(\mu \mathrm{g} / \mathrm{ml}) \\
\text { Fibrin plate test }\end{array}$ & $\begin{array}{l}0 \cdot 72 \pm 0 \cdot 09 \\
318 \pm 30 \\
2 \cdot 5 \pm 0 \cdot 21 \\
2 \pm 0 \cdot 46 \\
\text { No lysis }\end{array}$ & $\begin{array}{l}0.65 \pm 0.07 \\
318 \pm 30 \\
2 \cdot 4 \pm 0 \cdot 22 \\
1 \cdot 7 \pm 0 \cdot 35 \\
\text { No lysis }\end{array}$ & $\begin{array}{l}0 \cdot 63 \pm 0 \cdot 07 \\
319 \pm 31 \\
2 \cdot 35 \pm 0 \cdot 23 \\
1 \cdot 9 \pm 0 \cdot 38 \\
\text { No lysis }\end{array}$ & $\begin{array}{l}0.59 \pm 0.06 \\
300 \pm 38 \\
2 \cdot 30 \pm 0 \cdot 23 \\
1 \cdot 4 \pm 0 \cdot 34 \\
\text { No lysis }\end{array}$ & $\begin{array}{l}0.61 \pm 0.07 \\
293 \pm 27 \\
2 \cdot 33 \pm 0 \cdot 22 \\
1 \cdot 7 \pm 0 \cdot 35 \\
\text { No lysis }\end{array}$ & $\begin{array}{l}0.60 \pm 0.07 \\
349 \pm 33 \\
2 \cdot 28 \pm 0.23 \\
1 \cdot 7 \pm 0 \cdot 35 \\
\text { No lysis }\end{array}$ \\
\hline
\end{tabular}

Table I Mean results of euglobulin lysis times, assays of fibrinogen, plasminogen and fibrin degradation products, and fibrin plate tests estimated in subjects breathing room air, a hypoxic gas mixture, and a high oxygen concentration 
found that the greatest activity was in blood samples which they presumed had stagnated in the smaller vessels of the limbs, but clearly other factors, eg, a fall in $p \mathrm{H}$, could have been involved in these results. Similarly, venous occlusion has been shown to increase the fibrinolytic activity of the blood contained within the occluded segment (Clarke et al, 1960; Cliffton et al, 1961), and interpretation of these results is also difficult.

Tissue plasminogen activator release has been thought to be enhanced by tissue anoxia. Abrupt fibrinolytic activity following vasoconstriction or tissue anoxia has been cited as the cause of the rapid dissolution of blood clots after death from strangulation, drowning, and anaphylaxis (Lack, 1964), and enhanced fibrinolytic activity was demonstrated in almost all patients subjected to electroconvulsion shock (Sherry er al, 1959), tissue anoxia being assumed to be a major stimulus to increased fibrinolytic activity. Our results, obtained in a double-blind experiment, suggest that some mechanism other than uncomplicated anoxia may be responsible. Our observations also contrast with those of Harwig et al (1968) who reported that breathing oxygen at intervals enhanced blood fibrinolytic activity in both healthy subjects and in patients with chronic cor pulmonale.

While it is possible that chronic alteration in blood gas status may affect plasma fibrinolytic activity, our results suggest that in healthy subjects neither marked acute arterial hypoxia nor acute hyperoxygenation affect spontaneous plasma fibrinolytic activity. Some other mechanism must, therefore, be postulated to explain the changes in fibrinolytic activity found in anoxic limbs, in asphyxia, in occluded venous segments, and after electric shock.

This work was carried out whilst one of us (G.M.C.) was a Faulds research scholar of the University of Glasgow.

Thanks are due to Mrs C. Pidgeon and Mrs A. Sandiford for scientific assistance, to the medical Research Council for financial assistance, and to Professor A. S. Douglas for his interest in this work.

\section{References}

Alkjaersig, N., Fletcher, A. P. and Sterry, S. (1959). The mechanism of clot dissolution by plasmin. J. clin. Invest., 38, 1086-1095.

Bonnar, J., Davidson, J. F., Pidgeon, C. F., McNicol, G. P., and Douglas, A. S. (1969). Fibrin degradation products in normal and abnormal pregnancy and parturition. Brit. med. J., 3, 137-140.

Clarke, R. L., Orandi, A., and Cliffton, E. E. (1960). Induction of fibrinolysis by venous obstruction. Angiology, 11, 367-370.

Cliffton, E. E., Clarke, R. L., and Murphy, J. (1961). Studies on fibrinolytic activity with venous occlusion: Treatment of thrombophlebitis. Surgery, 50, 644-650.

Dubber, A. H. C., McNicol, G. P., Uttley, D., and Douglas, A. S. (1968). In vitro and in vivo studies with trasylol, an anticoagulant and a fibrinolytic inhibitor. Brit. J. Haemat., 14, $31-49$.

Kwaan, H. C., Lo, R., and McFadzean, A. J. S. (1958). On the lysis of thrombi experimentally produced within veins. Brit.J. Haemat., 4, 51-62.

Kwaan, N. C., and McFadzean, A. J. S. (1956). The inhibition of clot lysis by corticotrophin. Lancet, 1, 136-137.

Lack, C. H. (1964). Proteolytic activity and connective tissue. Brit. med. Bull., 20, 217-222.

Lieberman, J., and Kellogg, F. (1967). Hyaline membrane formation and pulmonary plasminogen activator activity in various strains of mice. Pediatrics, 39, 75-77.

McNicol, G. P., and Douglas, A. S. (1964). The fibrinolytic enzyme system. In Recent Advances in Clinical Pathology, series 4, edited by S. C. Dyke, pp. 187-208. Churchill, London.

Merskey, C., Kleiner, G. J., and Johnson, A. J. (1966). Quantitative estimation of split products of fibrinogen in human serum. Blood, 28, 1-18.

Mills, R. J. (1971). An improved end-tidal breathsampler for pulmonary function assessment. (In preparation.)

Nilsson, I. M., and Olow, B. (1962). Fibrinolysis induced by streptokinase in man. Acta chir. scand., 123, 247-266.

Ratnoff, O. D., and Menzie, C. (1955). Estimation of fibrinogen in small samples of plasma. In Blood Coagulation, Haemorrhage and Thrombosis, edited by L. M. Tocantins and L. A. Kazal, pp. 224-226. Grune and Stratton, New York.

Remmert, L. F., and Cohen, P. P. (1949). Partial purification and properties of a proteolytic enzyme of human serum. J. biol. Chem., 181, 431-448. 